\title{
The Effect of Nutritional Lipid Supplementation on Serum Lipid Levels and Effectiveness of Antitubercular Chemotherapy
}

\author{
Iyamu O.A. ${ }^{1, *}$, Ugheoke J.E ${ }^{2}$, Ozor M.O. , Airhomwanbor K.O. ${ }^{4}$, Eidangbe A.P. ${ }^{5}$, Idehen I.C. ${ }^{6}$, Okhiai O. ${ }^{7}$, \\ Akpede $\mathbf{N}^{8}$

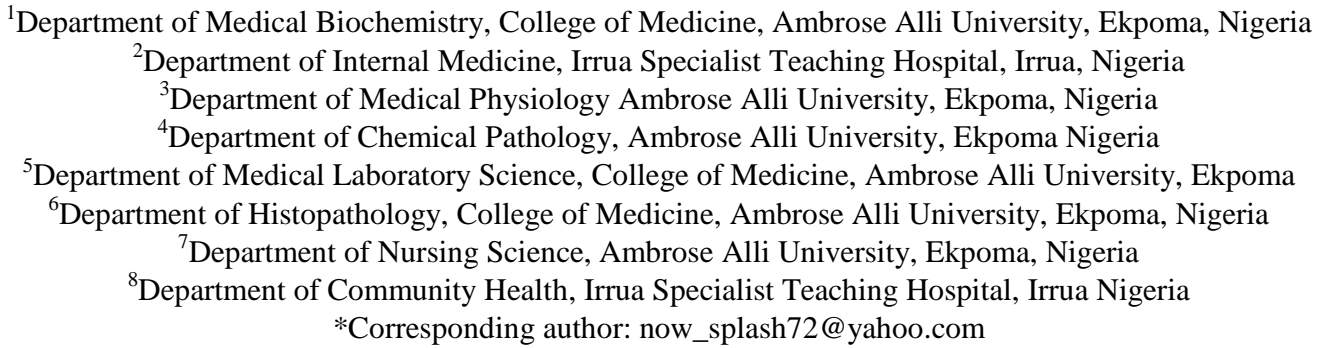

Received February 07, 2014; Revised April 28, 2014; Accepted May 22, 2014

\begin{abstract}
The effect of serum lipid levels on the incidence and management of tuberculosis has recently been brought to the fore. The aim was to see the effect of nutritional supplementation on susceptibility of organisms of the mycobacterium tuberculosis complex to some known antitubercular drugs via effect on serum lipid levels. Blood samples were collected for baseline estimation of serum lipids from 250 tuberculosis patients who were then allocated into four groups including: those taking drugs for tuberculosis(antitubercular drugs) treatment only, those on antitubercular drugs and one boiled egg daily, those on antitubercular drugs and fish oil (1000 IU/day), and those on antitubercular drugs and both egg and fish oil daily, all for a three month duration, at the end of which blood samples were collected for estimation of serum triglycerides, total cholesterol (TC), high density lipoprotein (HDLC), low density lipoprotein cholesterol (LDL-C), very low density lipoprotein cholesterol (VLDL-C), and Phospholipids, using appropriate methods. Results shows that though treatment with antitubercular drugs and supplementation with fish oil led to increases in serum lipid levels which were ab initio lower in tuberculosis patients than Healthy controls, supplementation with boiled egg led to a higher increase in serum lipid levels. Supplementation with fish oil also led to the greatest decreases in antitubercular drug resistance. It is thus suggested that supplementation with lipid rich foods in tuberculosis treatment will decrease anti tuberculosis drug resistance and help the global campaign on tuberculosis eradication.
\end{abstract}

Keywords: tuberculosis, Serum lipids, drug resistance, boiled egg, fish oil

Cite This Article: Iyamu O.A., Ugheoke J.E, Ozor M.O., Airhomwanbor K.O., Eidangbe A.P., Uwuigbe M., Idehen I.C., and Okhiai O, "The Effect of Nutritional Lipid Supplementation on Serum Lipid Levels and Effectiveness of Antitubercular Chemotherapy.” American Journal of Biomedical Research, vol. 2, no. 2 (2014): 36-41. doi: 10.12691/ajbr-2-2-4.

\section{Introduction}

Tuberculosis, the great white scourge [1] and John Bunyan's "Captain of all these men of death" $[2,3]$ is a worldwide bacterial infection, sometimes acute but more often chronic, caused mainly by infectious organisms of the mycobacterium tuberculosis complex [4]. Among communicable diseases, tuberculosis is the second leading cause of death worldwide, killing 2 million people each year [5] and the risk factors for the disease include overcrowding, malnutrition, smoking, depressed immunity etc [6].

According to the WHO report [7] there were an estimated 8.7 million new cases of Tuberculosis (13\% infection with tuberculosis) and 1.4 million people died from the disease, including almost 1 million deaths among HIV - negative individuals and 430,000 among people who are HIV positive. The WHO global program on tuberculosis advocates for the use of directly observed treatment short course (DOTs) for all patients which involves giving isoniazid, rifampicin, pyrazinamide and ethambutol for two months, then Isoniazid and rifampicin only for further four months and the patient is considered cured at six months [8].

The disease remains an issue of great public health concern today despite the fact that effective treatment has been available for over fifty years [9]. Resistance of the tuberculosis bacilli to the antitubercular drugs is an important factor. Since 2006 emergence of extensively 
drug resistant TB has been an important issue and is considered a serious threat to global TB control [10].

According to WHO [11] multidrug resistant tuberculosis (MDR-TB) is a form of TB caused by bacteria that does not respond to at least Isoniazid and rifampicin, the two most powerful first line (or standard) anti-TB drugs; and extensively drug-resistant TB (XDR$\mathrm{TB}$ ) is a form of multidrug tuberculosis that respond to even fewer available medicine, including the most effective second-line anti-TB drugs.

The lipid content of the causative organisms may influence the pathophysiology, clinical characteristics, susceptibility to relevant drugs, and progression, of the disease. The high lipid content of the pathogen accounts for many of its clinical properties [12].

Serum level of total cholesterol have been found to be low in patients with pulmonary tuberculosis and a cholesterol rich diet might accelerate sterilization of the sputum in these patients [13]. HDL cholesterol has been shown to be low in patients with inflammatory diseases such as pneumonia and tuberculosis $[14,15]$ and a close relationship has been demonstrated between acute phase reactant and HDL cholesterol. Several authors [13,15,16] found serum lipid levels, especially of HDL, to be low in pulmonary TB when compared to the healthy group and emphasized that low level of HDL in TB might be related to acute phase proteins induced by medication during the inflammatory process, and this was thought to be due to possible lipoprotein oxidation. [17] According to Perez Guzman et al [18] low serum cholesterol may be a risk factor for the development of pulmonary TB.

Literature is relatively sparse on the relationship between blood serum lipids level and the incidence of antituberculoar drug resistance of organism of the mycobacterium tuberculosis complex. The aim of this work is thus to assess the levels of serum lipids including TC, TGs, HDL-C, LDL-C and VLDL-C and see the effects that changes in levels of some of these lipids will have on sensitivity of the organism to antitubercular drugs. The results may give useful hints on whether or not lipidrich diet should be prescribed in the management of tuberculosis. This should be an important contribution to the global TB eradication campaign

\section{Materials and Methods}

\subsection{Sample Population}

Patients attending the government-owned Central Hospital Benin City and the privately owned Mount Gilead hospital were used for the study. Informed consent was sought and any patient disposed to participating in the study was asked to volunteer his sputum and blood sample. In all a total of 250 patients were used. Baseline blood samples were collected for the determination of serum lipid concentration of lipids including triglycerides, total cholesterol, very low density lipoproteins, low density lipoproteinss, high density lipoproteins, and phospholipids. The patients were then divided into four different groups of 65 patients each as follows:

Group 1 patients consisted of patients taking only antitubercular drugs according to the regular treatment short course (directly observed) regime.
Group 2 patients were asked to take egg daily along with their anti-tuberculosis drugs for a period of three months.

Group 3 patients were asked to take 1 capsule of fish oil (1000 iu daily) along with their daily anti-tuberculosis drugs for period of.

Group 4 patients were asked to take 1 capsule fish oil and an egg daily.

At the end of the three months blood and sputum samples were collected from patients in all the groups for determination of serum levels of the lipids, and culture and sensitivity testing respectively.

65 other apparently healthy subjects were used as control.

\subsection{Inclusion Criteria}

1. Only newly diagnosed tuberculosis patient yet to commence treatment were admitted to the study.

2. Those habitually on fish oil supplement were excluded.

3. Only stable patients were included.

4. A valid written informed consent was a prerequisite for enrolling a subject in the study.

5. Only those with recent evidence of disease- free chest Xray were included as controls.

\subsection{Sputum Collection}

Sputum samples were collected in sterile capped containers and were processed quickly. Where the samples could not be processed immediately the samples were stored at $4^{\circ} \mathrm{C}$ till evening.

\subsection{Blood Collection}

From each patient about $5 \mathrm{mls}$ of blood was collected by venipuncture of the antecubital vein and centrifuged to separate the serum. The serum was then stored at $-20^{\circ} \mathrm{C}$. Determination of the concentration of the various lipids was then done.

\subsection{Sputum Microscopy and Culture}

Sputum samples were subjected to Ziehl Nielson's acid fast staining to look for the presence of acid-fast bacilli. Samples were decontaminated by N-acetyl cystein Sodium hydroxide (NALC - NaOH) method, cultured in Loweinsten Jensen medium and identified according to the method of Canneti et al [19]. The cultures were then inoculated and incubated ay $37^{\circ} \mathrm{C}$ for 6 weeks and examined every week to look for the presence of mycobacterial growth. Where growth on LJ medium was suspected ZN staining was applied as a confirmatory test for AFB. Positive growths were sub cultured on fresh LJ medium for further identification and sensitivity.

\subsection{Biochemical identification}

Identification of mycobacterial isolates after primary culture on LJ medium was done by growth rate, colony morphology, color, niacin production, nitrate production, catalase production at $68^{\circ} \mathrm{C}$ [20].

\subsection{Drug Susceptibility testing}


This was done for first line antitubercular drugs including Rifampicin (2 ug/ml), Isoniazid (1 ug/ml), ethambutol (2 ug/ml) and Streptomycin (4 ug/ml) using the standard proportion method by Canneti et al [19]. In brief, growth from LJ positive slopes was suspended in normal saline and vortexed for 10-15 min. The suspension was allowed to settle for 15-20 min and compared with standard. Then 1/100 and 1/10,000 dilutions of the above suspension were compared in normal saline and used as inoculums. For each drug and for each dilution 100ul of the inoculum was used to inoculate two drug-free and two drug-containing LJ medium. Standard reference strain H37RV was used as control with each batch of sensitivity the MR isolates were further screened for XDR-TB by performing second line testing for Ofloxacin (2 ug/ml) and Karamycin $(20 \mathrm{ug} / \mathrm{ml})$ in liquid culture by BACTEC MERIT 590 [20].

Antibiotic resistance (\%) was calculated on an antibiotic treated medium as:

$$
\frac{\text { Total cultures }- \text { positive growths }}{\text { Total cultures }} \times 100
$$

\subsection{Biochemical Assays}

\subsubsection{Total Cholesterol}

This was estimated using the method of Fredrickson et al [22]. In principle the method involves the following reactions:

$$
\begin{aligned}
& \text { Cholesterol esters }+\mathrm{H}_{2} \mathrm{O} \stackrel{\text { cholesterol esterase }}{\longrightarrow} \\
& \text { cholesterol + fatty acids } \\
& \text { Cholesterol }+\mathrm{H}_{2} \mathrm{O}_{2} \stackrel{\text { cholesterol Oxidase }}{\longrightarrow} \\
& \text { Cholesternone }+\mathrm{H}_{2} \mathrm{O} \\
& \stackrel{\mathrm{H}_{2} \mathrm{O}_{2}+4-\text { Aminoantipyrine }+3,5 \text { Dichlorophenol }}{\text { peroxidase }} \text { colouredquinonic Derivatives }+4 \mathrm{H}_{2} \mathrm{O}
\end{aligned}
$$

An already prepared kit (Quinica clinica applicada) was used, the contents included cholesterol oxidase, cholesterol esterase, peroxidase, $n$

on-reactive stabilizers, phosphate buffer, phenol, 2,5Dichlorophenol and 4-aminoantipyrone. Storage was at 2$8^{\circ} \mathrm{C}$, protected from light. Three test tubes $1,2,3$ were used and the content of the text tubes produced were

\begin{tabular}{|c|c|c|c|}
\hline & Blank & Sample (M/s) & Standard (m/s) \\
\hline & 1 & 2 & 3 \\
\hline Sample (m/s) & - & 0.02 & - \\
\hline Standard (m/s) & - & - & 0.02 \\
\hline Working reagent (m/s) & 2.00 & 2.00 & 2.00 \\
\hline
\end{tabular}

The contents of each was mixed well and incubated for $15 \mathrm{~min}$ at $37^{\circ} \mathrm{C}$ and read at $546 \mathrm{~nm}$ wavelength. The content of cholesterol (mg/dl) was calculated as

$$
\frac{\mathrm{OD}_{\text {sample }}}{\mathrm{OD}_{\text {standard }}} \times 200=\mathrm{mg} \text { of cholesterol } / \mathrm{dl} \text { serum }
$$

The units in $\mathrm{mg} / \mathrm{dl}$ can be converted to mmol/litre by multiplying with 0.0259 .

\subsubsection{HDL Cholesterol}

This was estimated using the Dextran sulphate-mg ${ }^{2+}$ method of Gotto [23]. In principle LDC and VLDL (low and very low density lipoprotein) are precipitated from serum by the action of a polysaccharide in the presence of a divalent cation. The reagent include precipitant solution (Ref. 993885), Dextran Sulphate, Magnesium acetate and stabilizers. One drop of precipitant solution was added to $0.3 \mathrm{ml}$ of sample, mixed, incubated at room temperature $\left(20-25^{\circ} \mathrm{C}\right)$ and centrifuged at $2000 \mathrm{~g}$ for $15 \mathrm{~min}$. The supernatant was used. Three test tubes 1, 2, 3 were prepared with the following contents.

\begin{tabular}{|c|c|c|c|}
\hline & 1 & 2 & 3 \\
\hline Supernatant & - & 0.02 & - \\
\hline Standard & - & - & 0.02 \\
\hline Working reagent & 2.00 & 2.00 & 2.00 \\
\hline
\end{tabular}

The content of each was well mixed, incubated for 5 $\min$ at $37^{\circ} \mathrm{C}$, and read at a wavelength of $546 \mathrm{~nm}$.

The concentration of HDL - Cholesterol was calculated as

$$
\frac{\mathrm{OD}_{\text {sample }}}{\mathrm{OD}_{\text {standard }}} \times 200=\mathrm{mg} \mathrm{HDL}-\mathrm{C} / \mathrm{dl}
$$

\subsubsection{Triglycerides}

This was done by the method of Trinder [24]. In principle the method involves

Triglycerides $\stackrel{\text { Lipase }}{\longrightarrow}$ Glycerol + Fatty acid

Glycerol + ATP Glycerol kinases Glycerol - 3- Phosphate + ADP

Glycerol-3-Phosphate $+\mathrm{O}_{2} \stackrel{\text { Glycerol-3-Phosphate }}{\longrightarrow}$

Oxidase Dihydroacetone phosphate $+\mathrm{H}_{2} \mathrm{O}$

$2 \mathrm{H}_{2} \mathrm{O}+4-$ aminoantipyrine peroxidase

$\stackrel{\text { Quinoneimine }}{\longrightarrow}-\mathrm{HCL}+4 \mathrm{H}_{2} \mathrm{O}$

The reagent kits consisted of Freeze-dried enzymes (Re. 99026), Buffer solution (Ref. 999618), and standard (Ref. 996277) equivalent to $200 \mathrm{mg} / \mathrm{dl}(2.29 \mathrm{mMol} / \mathrm{L})$. The working reagent consisted of $40 \mathrm{mMol} / \mathrm{L}$ buffer $\mathrm{pH}$ 7.5, 6 $\mathrm{mMol} / \mathrm{L}$ 4-chlorophenol, $0.5 \mathrm{mmol} / \mathrm{l}$ 4-aminoantipyrine, 1 $\mathrm{mMol} / \mathrm{L}$ ATP, $5 \mathrm{mMol} / \mathrm{L} \mathrm{mgCl}_{2}$, $450 \mathrm{u} / \mathrm{L}$ Glycerol kinase, $1500 \mathrm{u} / \mathrm{L}$ Glycerol-3-Phosphate oxidase, $500 \mathrm{u} / \mathrm{L}$ peroxidase, $150,000 \mathrm{u} / \mathrm{L}$ lipases and non reactive stabilizers.

Three test tubes were prepared as follows

\begin{tabular}{|c|c|c|c|}
\hline & 1 & 2 & 3 \\
\hline Sample (m/s) & - & 0.02 & - \\
\hline Standard (m/s) & - & - & 0.02 \\
\hline Working reagent (m/s) & 2.00 & 2.00 & 2.00 \\
\hline
\end{tabular}

The content of each was mixed well, incubated for 5 min at $37^{\circ} \mathrm{C}$, and read at a wavelength of $546 \mathrm{~nm}$.

Calculations

$$
\frac{\text { OD }_{\text {Supernant }}}{\text { OD }_{\text {Standard }}} \times 200 \mathrm{mg} \text { triglycerides / dl }
$$

$\mathrm{Mg} / \mathrm{dl}$ may be converted to $\mathrm{mmol} / \mathrm{L}$ as $\mathrm{mg} / \mathrm{dl}$ x 0.01143 $=\mathrm{mMol} / \mathrm{L}$

\subsubsection{Very Low Density Lipoprotein Cholesterol (VL} DL-C).

This was calculated from triglycerides by using the Fridewald equation [25] as:

VL DL-C $(\mathrm{mg} / \mathrm{dl})=$ Triglycerides $(\mathrm{mg} / \mathrm{dl}) / 5$

\subsubsection{Low density lipoproetein-cholesterol (LDL-C)}


The polyvinylsulphate (PVS) method of Bergmenyer [26] was used. In principle the LDL-Cholesterol is determined as the difference between total cholesterol and the cholesterol content of the supernatant after precipitation of LDL fraction by polyvinyl sulphate (PVS) in the presence of polyethylene-glycol monomethyl ether.

The reagents were precipitant solution (Ref 990610) and the kit containing $0.7 \mathrm{~g} / \mathrm{l}$ of polyvinyl sulphate, $5.0 \mathrm{~m}$ Mol/L sodium EDTA, polyethylene glycol monomethyl ether (170 g/L), and stabilizers.

To prepare the supernatant 3 drops of precipitant solution was added to $0.2 \mathrm{ml}$ of sample, mixed, incubated for $15 \mathrm{~min}$ at room temperature, centrifuged at $2000 \mathrm{~g}$ for $15 \mathrm{~min}$, and the supernatant used for estimation. Calculation was done as:

\section{LDL - Cholesterol $(\mathrm{mg} / \mathrm{dl})=$ Total cholesterol $(\mathrm{mg} / \mathrm{dl})$ -1.5 x Supernatant cholesterol $(\mathrm{mg} / \mathrm{dl})$.}

\subsubsection{Phospholipids}

The colorimetric method of Gomorris [27] was adopted. In principle the inorganic Phosphorus in serum reacts with Molybdic acid to form a Phosphomolybdic acid complex, which is reduced by ammonium iron (ii) Sulphate to Molybdenium blue, measured at $690 \mathrm{~nm}$. The reagent kit was made up of Molybdate reagent, reductant (Ammonium iron II SulphateHexhydrate), redutant diluents (0.43N Sulphuric acid and surfactant) and a standard solution of Phosphorus (1.61 mMol/L). Three test tubes were prepared with the following content.

\begin{tabular}{|c|c|c|c|}
\hline & Blank & Sample (M/s) & Standard (m/s \\
\hline & 1 & 2 & 3 \\
\hline Working reagent & 1.0 & 1.0 & 1.0 \\
\hline Deionized water & 0.03 & - & - \\
\hline Standard (m/s) & - & $-0.03 \mathrm{~m} / \mathrm{l}$ & - \\
\hline Sample & - & - & 0.03 \\
\hline
\end{tabular}

The content of each of the tubes was well mixed and allowed to stand for $10 \mathrm{~min}$ at $25^{\circ} \mathrm{C}$ and read at $690 \mathrm{nM}$. The phospholipid content was calculated as

[Phospholipid $]=[\mathrm{Pi}] \times 25$

$[\mathrm{Pi}]=$ Absorbance of Sample $\mathrm{x}$ Absorbance of Standard

\subsection{Statistical Analysis}

The statistical program for the social sciences (SPSS) version 17.0 was used to determine the means of the serum concentration of the various classes of lipids.

\section{Results}

The results of the quantitative tests for the various lipid types and the observed incidence of antitubercular drug resistance for the various groups of patients are presented in the tables below.

Table 1. Values of various serum lipids for various experimental groups

\begin{tabular}{|c|c|c|c|c|c|c|}
\hline & Control & Baseline & Group 1 & Group $2^{\text {Group } 4}$ & Group 3 \\
\hline TG & $126.60 \pm 2.0696^{\mathrm{a}}$ & $63.20 \pm 2.0392^{\mathrm{b}}$ & $148.52 \pm 3978^{\mathrm{c}}$ & $103.87 \pm 4.0252$ & $151.7 \pm 3.4325^{\mathrm{c}}$ & $102.55 \pm 0.973$ \\
\hline PLP & $161.50 \pm 1.6365^{\mathrm{a}}$ & $231.80 \pm 5.593^{\mathrm{b}}$ & $201.68 \pm 3.8858^{\mathrm{b}}$ & $218.43 \pm 3.4136^{\mathrm{c}}$ & $217.68 \pm 5.2266^{\mathrm{c}}$ & $219.82 \pm 2342^{\mathrm{c}}$ \\
\hline TC & $185.92 \pm 2.2506^{\mathrm{a}}$ & $116.90 \pm 3.7824^{\mathrm{a}}$ & $184.942 .3654^{\mathrm{a}}$ & $208.148 \pm 1.0524^{\mathrm{b}}$ & $189.94 \pm 7.2545^{\mathrm{a}}$ & $209.36 \pm 4.7804^{\mathrm{b}}$ \\
\hline HDLC & $57.40 \pm 0.4541^{\mathrm{a}}$ & $33.62 \pm 0.3333^{\mathrm{b}}$ & $41.28 \pm 0.2485^{\mathrm{b}}$ & $52.4925 \pm 6.2459^{\mathrm{a}}$ & $31.42 \pm 1.3544^{\mathrm{b}}$ & $53.121 \pm 3303^{\mathrm{a}}$ \\
\hline LDLC & $64.50 \pm 2.8647^{\mathrm{a}}$ & $57.16 \pm 2.1297^{\mathrm{b}}$ & $50.08 \pm 03738^{\mathrm{b}}$ & $51.00 \pm 3.1121^{\mathrm{b}}$ & $49.89 \pm 3.2461$ & $51.89 \pm 3.8751^{\mathrm{b}}$ \\
\hline VLDLC & $25.28 \pm 0.4084^{\mathrm{b}}$ & $12.64 \pm 0.40^{\mathrm{a}}$ & $29.70 \pm 0.2796^{\mathrm{b}}$ & $28.94 \pm 2.3874^{\mathrm{b}}$ & $30.26 \pm 3.4861^{\mathrm{c}}$ & $30.45 \pm 10943^{\mathrm{c}}$ \\
\hline
\end{tabular}

Note: Values with different alphabets on the same row differ significantly

Table 2. Incidence of resistance to antituberculosis drugs by organisms of the Mycobacterium tuberculosis complex (\%)

\begin{tabular}{|c|c|c|c|c|c|c|}
\hline \multirow{2}{*}{ Anti TB drug } & \multicolumn{6}{|c|}{ Antibiotic Resistance (\%) } \\
\hline & Baseline & Group 1 & Group 2 & Group 3 & Group 4 & P-value \\
\hline INH & $1.75^{\mathrm{a}}$ & $1.12^{\mathrm{c}}$ & $0.05^{\mathrm{a}}$ & $1.08^{c}$ & $0.05^{\mathrm{a}}$ & $\mathrm{P}<0.05$ \\
\hline ETB & $1.85^{\mathrm{a}}$ & 1.73 & $0.10^{\mathrm{b}}$ & 1.75 & $0.13^{b}$ & $\mathrm{P}<0.05$ \\
\hline RFP & $0.99^{\mathrm{a}}$ & $9.98^{\mathrm{a}}$ & $0.07^{b}$ & $0.99^{\mathrm{a}}$ & $0.06^{b}$ & $\mathrm{P}<0.05$ \\
\hline STM & $1.83^{b}$ & $1.69^{b}$ & $0.90^{\mathrm{a}}$ & $1.70^{\mathrm{b}}$ & $0.75^{\mathrm{a}}$ & $\mathrm{P}<0.05$ \\
\hline OFX & $2.46^{\mathrm{a}}$ & 2.16 & 1.25 & 2.08 & $1.22^{b}$ & $\mathrm{P}<0.05$ \\
\hline KNC & $3.56^{\mathrm{a}}$ & 3.10 & $1.25^{b}$ & 3.06 & $1.22^{b}$ & $\mathrm{P}<0.05$ \\
\hline
\end{tabular}

Key

Baseline: All subjects at diagnosis before any form of therapeutic intervention.

Group 1: Tuberculosis patients after 3 months treatment with standard antitubercular drugs (first and second line) only.

Group 2: Tuberculosis patients after 3 months of treatment with standard anti tuberculosis drugs (first and second line) and daily supplementation with one boiled egg.

Group 3: Tuberculosis patient after 3 months treatment with standard anti tubercular drugs (first and second line) and daily supplementation with commercial fish oil preparation.
Group 4: Tuberculosis patients after 3 months treatment with standard anti tuberculosis drugs (first and second line) and daily supplementation with both boiled egg (one daily) and first oil (1000 iu daily).

\section{Discussion}

The Global eradication of tuberculosis has been the target of concerned organizations largely coordinated by the WHO. Despite the fact that effective drugs have been available for years millions of cases of the disease still abound. The emerging problem of the drug-resistant strains of the mycobacterium tuberculosis complex has also contributed to the difficulty of TB eradication. Nutritional considerations have not been so much given 
attention as a potential way out of the debacle. The role of good nutrition in any disease condition cannot be overemphasized especially as it relates to the role of nutrition in immunity.

The importance of dietary lipids in the management of tuberculosis has only recently become a subject of discourse within the global medical community. The contribution of several authors [13,15,16,18] have been mentioned. From Table 1 it can be seen that at baseline the serum levels of the lipids, apart from the phospholipids, are lower than the levels of healthy (control) subjects. Treatment with antitubercular drugs (group 2 patients) however raised the levels of the serum lipids. It is observed that egg supplementation (group 2) significantly increased the serum levels of the plasma lipids (Group 2). There was a non-statically significant increase brought about by fish oil supplementation (group 3) but the increase brought about by both egg and fish oil supplementation did not appear to be additive (group 4).

From Table 2 it can be seen that there were statistically significant differences among the levels of anti TB drug resistance among the group. This was seen for all the first and second line drugs used. The incidence of resistance was most reduced in the group in which members had egg supplementation. Also it was observed that only fish oil supplementation did not significantly reduce incidence of resistance and that combined egg and fish oil supplementation produced an effect resembling that with only egg supplementation.

The values of lipid profile parameters derived from the serum of healthy controls fall within normal levels according to some earlier studies by several independent authors [28,29,30]. The values of cholesterol (all varieties) were found to be lower in newly diagnosed tuberculosis patients yet to commence antitubercular medication. Cholesterol is the most studied lipid in this direction and the works of various authors have found that low cholesterol in the serum of tuberculosis patients when compared to healthy subjects and household contacts. Some even proposed that hypocholesterolemia is a risk factor for tuberculosis $[13,15,16,18]$. The finding that treatment with antitubercular drugs significant increased the lipid profile is consistent with the findings by Saraswatty and Shynale-Der [31] even though it contrasts Porter et al who found no effect on serum cholesterol but a seasonal effect on serum triglycerides. This suggest that a decreased lipid profile is part of the pathophysiological mechanism of tuberculosis infection.

Omega 3 fatty acids are the principal lipid component of fish oil. We found some statistically insignificant increases in the lipid profile. This is at variance with the work of Stark et al [33] which found a 26\% lower serum TG concentration and a $28 \%$ lower overall ratio of serum TG to HDL cholesterol. Lipid profile was found to be increased by boiled egg supplementation. This agrees with Mayurasakorn et al [33] who found that a 12-week egg consumption significantly increased serum total cholesterol and concluded that in the majority of healthy adults, an addition of one egg per day to normal fat diet could raise HDL-C level and decrease the ratio of total cholesterol to HDL-C and this might benefit blood cholesterol even though Porter et al did not find any such effect. Normal to high blood cholesterol, as against hypocholesterolamia is not commonly associated with the incidence of tuberculosis.

The lower incidence of antitubercular drug resistance with higher blood cholesterol in patients with egg supplementation suggest that factors which may help protect against hypocholesterolarmia should be adopted in tuberculosis management. We thus suggest that supplementation with cholesterol-rich preparations be an accompaniment of antitubercular drugs in TB management. Unfortunately the factor of age was not considered in this study and so further studies are needed to balance the beneficial effect of high serum cholesterol in TB management and protection against the risk of TB with its detrimental effects on cardiovascular health especially in older patients.

\section{References}

[1] Khan, AM. Role of a tuberculosis Sanatorium in the national campaign against white scourge. Pak J. Health, 1959 9:148-51. 1959.

[2] Michael, D and Iseman, MD. Tuberculosis, a captain, preumococcus a lieutenant. Arch Intern. Med. 151 (10): 21-30. 1991.

[3] Heather Milburn. Key issues in the diagnosis and management of tuberculosis. JR SOC Med. 100 (3): 134-141. 2007.

[4] Vasconcellos SE, Huard RC, Niemann S, Kremer K, Santis AR, Syffys, RN and HO, JL. Distinct genetopy profiles of the two major clades of mycobacterium africanum. BMC infect Dis 10: 80 . 2010.

[5] Frieden TR, Sterling TR, Munsiff SS, Watt CJ, and Dye C. Tuberculosis, Lancet 362 (9387): 857-99. 2003.

[6] Schmidt, CW. Linking TB and the environment. Environ Health Persp. 116 (11): A478-A485. 2008.

[7] WHO Global Tuberculosis report, 2012.

[8] Awofeso N. Antituberculosis medication side effects constitute a major factor for poor adherence for tuberculosis treatment. Bull World Health organization. 2008.

[9] Dohn, PJ, Raviglore MC. A Global tuberculosis incidence and mortality during 1999-2000). Bull of the World Health Organ 72 (2): 212-220. 2002.

[10] Porwal C, Kansh A, Makkar N, Banavaliken JN, Banif M, Singla R, Bhatnagar AK, Behara D, Akande JN, Singh UB. Incidence and risk factors for extensively drug-resistant tuberculosis in Delhi region PLOs one 8 (2): e 55299. 2013.

[11] WHO Global Tuberculosis Report, 2013.

[12] Southwick F. "Chapter 4: Pulmonary infections". Infectious diseases: A clinical short course, $2^{\text {nd }}$ ed, McGraw-Hill Medical Publishing Division. Pp 104, 313-4. 2007.

[13] Perez-Guzman C, Vargas MH, Quinonez F, Bazavilvazo N, Aguilar A.. A cholesterol-rich diet accelerates backeriologic sterilization in pulmonary tuberculosis. Chest; 127: 643-51. 2005.

[14] Rodriguez-Roguero JJ, Iglesias CG, Vasquez M, Poigueras I, Braga S, Bustillo E, Mosquera JA.. Variation in plasma lipid and lipoprotein concentrations in community-acquired pneumonia in a 6-month prospective study. Eur J. Clin Chem Clin Biochem. 34 (3): 245-9.1996.

[15] Deniz O, Tozkoparan E, Yaman H, Cakir E, Gumus S, Ozcan O, Boslar U, Bilgin H, Ekiz K. Serum HDL-C levels, log (TG/HDLC) values and serum total cholesterol/HDL-C ratios significantly correlates with radiological extent of disease in patients with community-acquired pneumoma. Clin Biochem, 39: 287-92. 2006.

[16] Volpato S, Palnuieri E, Felin R, Zulian, G. Acute phase markers are associated with reduced plasma lipid concentration in a population of hospitalized elderly patients. Genotology 2 46:22-7. 2000.

[17] Cabana VG, Siegel JN, Jabesim SM. Effects of the acute phase response on the concentration and density distribution of plasma lipids and apolipoporteins. J. Lipid Res 30: 39-49. 1989.

[18] Perez-Guzman C, Vargas MH, Salas-Martir C, Fredo-Santa Cruz T, Gallgos-Discua C, Flores-Lopez F. Rev Med Inst. Mex Seguro SOC 46 (3): 247-52. 2008. 
[19] Canetti C, Froman F,Grosset J, Handuroy P, Langenova M, Mahler HT, Meissner G, Mitchison, DH ed Sula L.. Mycobacteria laboratory methods for testing drug sensitivity and resistance. Bull WHO 41:21-43. 1963.

[20] Setti S, Mewara A, Dhatwala SK, Singh H, Yadav R, Singh K,gupta D, Wanchu A. and Sharma M. Prevalence of multi drug resistance in mycobacterium isolates from HIV seropositive and seronegativepetients with pulmonary tuberculosis in north India. BMC Infectious Diseases, 13: 137. 2013

[21] Rusil-Gerdes S, Pfuffer GE, Casal M, Chadinde M, and Siddiqi S. Multicentre laboratory validation of the BACTEC MGIT 960 techniques for testing susceptibilities of mycobacterium tuberculosis to classical second line drug and newer antimicrobials. J. Clin Microbiol 44 (3): 688-692. 2006.

[22] Fredrickson, D.S., Levil R. L., and Lee R. S. Fat transport in lipoproteins-An integration approach to mechanisms and disorders. N. Engl. J. Med., 276: 273-281. 1967.

[23] Gotto M.A. Lipoprotein metabolism and the Etiology of hyperlipidemia. Hospital Practice 23: 1-4. 1998

[24] Trinder, P. Enzymatic calorimetric determination of triglycerides by GOP-PAP method. Ann. Clin Biochem, 6: 24-27. 1969.

[25] Fridewald, WT, Lavy RI Fredrickson, DS. Estimation to density lipoprotein without use of the preparative ultracentrifuge. Clin chem. 18: 499-502. 1972.

[26] Bergmenyer, HU. Ed. Methods of enzymatic analysis ( $3^{\text {rd }}$ Ed.), USA pp 154-160. 1985.
[27] Gomorris G. Colorimetric determination of serum phospholipids. J. Lab. Clin. Med, 27: 958. 1942

[28] Glewett, Hassem HA Bhanji RA, Okorodudu A, Vandorjagt DJ. Serum lipid profiles and risk of cardiovascular disease in three different male population in northern Nigeria. J. Health Popul Nutr. 20 (2): 168-74. 2002.

[29] Osuji CU, Omejua EG, Onwubuya EI, and Aheneka GI. Serum lipid profile of newly diagnosed hypertension patients in Nnewi, South-East Nigeria. Int. J. Hypertension Article ID 7104867 pgs. 2012.

[30] Akpa MR, Agomouh DI, Alasia DD. Lipid profile of healthy adult Nigerian in Port Harcourt, Nigeria. Nig. J, Med 15 (2): 137-40. 2006.

[31] Saraswatty SD, and Shyamala-Devi CS. Antitubercular drugs induced hepatic oxidative stress and ultrastructural changes in rats. Bruc infect Dis. 12 (suppl 1): pg 5. 2012.

[32] Stark KD, Park JE Maries VA and Holub BJ. Effect of a fish oil concentrate on serum lipid in hormone receiving and not relieving hormone replacement therapy in a placebo-controlled, double-bind trial. Am J. Chin Nutr. 72 (2): 389-394. 2000.

[33] Mayurasakorn K, Frisura W, Sitphahul P, Honglo PO. High density lipoprotein cholesterol change after continuous egg consumption in healthy adult.J Med. Assoc. Thai 91 (3): 400-2. 2008.

[34] Porter MW, Yamanaka S, Carlson D, and Flynn MA. Effect of dietary egg on serum cholesterol and triglycerides of human diet. Am J. Chin Nutr. 30 (4): 490-495. 1977. 